\title{
CREATING A MARKETPLACE OF IDEAS: EQUITY IN EDUCATION AND TECHNOLOGY DURING COVID-19
}

\author{
John W. Hatcher III and Takashi Crum \\ Southeastern Louisiana University SLU 10549, Hammond, LA. 70402, USA \\ New York City Department of Education, New York, New York 11201, USA
}

\begin{abstract}
This research study explored the issue of equity in education and technology during the COVID-19 pandemic. A virtual forum was created that included a panel of educators from across the United States to discuss educational challenges related to equity and the use of technology during their transition from physical classrooms to the virtual classroom setting. This research was intended to provide insight into the perceptions of some educators regarding equity in education and technology as students received instruction from home and teachers engaged a variety of online platforms to deliver instruction. In this study an interview protocol was used to facilitate action research with a focus group of educators in the context of a two hour and twenty minute Zoom session that generated relevant responses from participants. Effective communication from school leaders with educational stakeholder groups emerged as a major theme among study participants.
\end{abstract}

\section{KEYWORDS}

Equity in Education, Technology, Accessibility, Accountability, COVID-19

\section{INTRODUCTION}

During the first quarter of 2020 the world was hit by the COVID-19 pandemic, which led to schools across the United States closing for weeks at a time. School districts struggled to provide clear guidance about when and how schools would reopen as the 2019-20 school year came to an abrupt end for many school communities. The COVID-19 virus continued to rage as school leaders were left with the questions of how to continue to meet the academic needs of students, the instructional needs of teachers, as well as, the overall safety needs of their school communities. Stakeholder groups had to explore the question of how to reopen schools. Many were forced to transition from face-to-face instruction to a variety of virtual platforms and hybrid models in order to deliver instruction based on local infection rates. This study explored some of the inequities within the U.S. system of education, which were highlighted by the pandemic and could result in relevant changes to how students, teachers, and schools engaged in the teaching and learning process. This study further explored the perspectives of educational practitioners through a virtual forum, while examining nuanced practices that intimately embedded technology into our current system of education. The significance of this research will provide educational stakeholders with practical insights into creating a more equitable system of education during and post the COVID-19 pandemic.

\section{EQUITY IN EDUCATION DURING COVID-19}

Equity in education has been a struggle in the United States of America since the days of the landmark cases of Plessy versus Ferguson (1896) and the infamous Brown versus Topeka Board of Education (1954). In 2015, President Barack Obama signed into law the Every Student Succeeds Act, which highlighted “...equity by upholding critical protections for America's disadvantaged and high-need students" (https://www.ed.gov/essa). 
For the purposes of this study the investigators defined "equity," as the fair distribution of available resources based on the needs of students, teachers, schools, school districts, and states.

The overarching research question was, "What does equity in education and technology look like in schools during COVID-19?" The researchers hosted a two hour and twenty minute virtual forum entitled, "Creating a Marketplace of Ideas: Equity in Education and Technology during COVID-19.” The forum included a panel of six educators from across the United States, who collectively had more than 150 years of experience as educational practitioners. The virtual forum was organized into three 40 minute segments and was facilitated by three distinct cohorts of graduate students in educational leadership. There were 49 participants in the virtual forum hosted on the Zoom platform, while an additional audience participated by asking questions and making comments as the event was streamed live via Facebook. The three segments of the virtual forum had the following subtopics:

- Accessibility to Instruction and Technology during COVID-19

- Accountability of Principals, Teachers, \& Students during COVID-19

- School Leadership during the COVID-19 crisis

The virtual forum began with the research team presenting the overarching question for each panelist to introduce themselves and respond to the overarching research question. During the remainder of the forum participants engaged in a forum protocol of questions developed specifically to glean the perspectives of panelists related to the three subtopics of the forum. Each of the three segments of the forum ended with a five-minute period for audience participation in which other educators could pose follow-up questions to the panelists or share their perspective on the topic.

\subsection{Accessibility to Instruction and Technology During COVID-19}

Instructional equity became the focus of schools across the United States. The instructional platform offered in most school districts was remote with hybrid and face-to-face as secondary modes for instructional delivery. According to the Pew Research, analysis of 2015 American Community Survey Data, at least 15\% of U.S. households with school age children did not have access to high-speed internet and many households were low income. Panelist \#3 stated equity access starts with students' access to technology when schools network with local businesses since some offered cheaper and more affordable subscriptions for parents. While Panelist \#2 believed it was the schools' responsibility to procure grants and corporate partnerships to ensure students did not fall further behind academically. Puckett and Rafalow (2020) stated unequal access to technology was the first level of the digital divide with many students still unprepared for technology based-learning. As a result, Panelist \#1 incorporated the use of YouTube or Khan Academy as technological resources to illustrate complex concepts that provide visualizations and interactive learning for students to understand and apply their knowledge. Thus, policy and practice of using technological resources should be the focus for students to develop as scholars.

The practices utilized by Panelist \#1 were examples of the lasting effects of COVID-19 pandemic on the future of education. Panelist \#3 stated, "that technology is now the backbone of education, teachers are now being given more flexibility and control in how instruction is imparted to their students, while parents now have a better understanding of the school's function and standardized testing may become a thing of the past." As technology comes to the forefront of instruction, it should be integrated in partnership with all school stakeholders involved. According to Panelist \#1, school budgets will shift from purchasing only textbooks to technology and software and teachers' roles will change, requiring credentials for virtual learning for both teachers and administrators. Accessibility to instruction and technology requires monitoring outcomes and accountability in the use of technology and achievement to identify gaps along all socio-economic levels (Puckett \& Rafalow, 2020).

\subsection{Accountability of Principals, Teachers, \& Students during Covid-19}

Domaleski (2020) stated accountability during COVID-19 specifically 2020 is entirely offline; the U.S. Department of Education issued waivers to all 50 states and provided an opportunity to explore significant improvement to accountability. Districts, schools, and teachers created new and innovative ways to ensure academic success for all students. According to Panelist \#6, students have to learn therefore, teachers must be held accountable to teach and facilitate instruction. While Panelist \#2 believed that without evaluations teachers 
assumed they received a free pass; however, teachers still needed to provide documentation of their communication with parents, students, while demonstrating the delivery of instruction.

According to Panelist \#1, to support continuous student learning, school and district leaders should be held accountable for meeting the needs of all students by creating a contingency plan that provides computer hubs for the community. Panelist \#2 stated, "school districts have a responsibility to ensure students' needs are met because they receive grants, established corporate partnerships, and local funding." Panelist \#3 stated, "...teachers were given the authority not just to teach the script but engaging parents to work together to ensure students' success beyond standardized testing." Audience members in the backchannels commented that communication was key to understanding how accountability related to students receiving quality instruction. One audience member stated, "Schools established purposeful relationships with parents by communicating expectations and focused on what students were learning and not the time it took them to learn." Students were responsible for their attendance in whatever format instruction was delivered, while being actively engaged in the instructional activities designed and created by their teachers.

All stakeholders, districts, principals, teachers, students, and parents are responsible and are accountable for our evolving and increasingly digital communication in spite of COVID-19. Panelist \#3 stated, "Schools are institutions in which society replicates itself and are changing how education and instruction occurs as a means to address (highlighted) COVID issues." According to Panelist \#6, "as education shifts, the role of teachers and students shifts to include virtual learning credentials and tailoring the education to the student; preparing students to meet the demands of the 22nd Century."

\subsection{School Leadership during the Covid-19 Crisis}

Leadership researcher Paul Hersey (Schermerhorn, 1997) stated, "Successful leaders are those who can adapt their behavior to meet the demands of their own unique situation." Hersey went on to describe situational leadership as the interaction between the directions given by the leader, the amount of socio-emotional support the leader provides, and the preparedness of those charged with executing the task. The early months of the COVID-19 pandemic found school leaders challenged by a myriad of questions surrounding school safety, instructional delivery methods, technology resources, and professional development for teachers just to name a few. In order to address these challenges our panelists were presented with a series of questions developed to share experiences and insight about how to remain effective as a school leader during COVID-19.

Throughout this school leadership segment of the forum there was a major theme that emerged from participants' responses in support of communication as a critical aspect of the school leader's behaviors. One of the questions presented in this segment of the forum was, "How do administrators and teachers plan for the delivery of instruction for the 2020-21 school year? Participants communicated that multiple scenarios and plans were needed, while school leaders engaged all stakeholder groups. Panelist \#4 suggested a town hall style meeting where plans and procedures were shared and stakeholders have the opportunity to give input and ask questions. Panelist \#4 then emphasized, "All stakeholders in the school are (should be) involved in the decision making." Another question asked in this segment of the forum was, "How can we (school leaders) ensure that the messages we communicate are being received? Panelist \#1 stated that, "Information and communication are key during this time (of COVID-19)." Panelist \#1 shared that school leaders must establish a variety of communication channels, such as, email, text message, and social media platforms in order to disseminate information to all stakeholders, while also managing for any harmful mis-information. An additional question posed during this school leadership segment of the forum was, "How will an administrator advise teachers to compensate for the lack of in-person feedback when they may only see students' faces on a computer screen? Participant \#6 expressed that communication must be ongoing and that it should be used as an accountability measure in which teachers are constantly assessing students' needs. This ongoing communication is also necessary for engaging with parents and other stakeholders.

The school leadership segment of the forum highlighted participants' perceptions of the need for effective and efficient communication skills and behaviors demonstrated by school leaders. Meaning clear directions, an awareness of student, teacher, and school needs. In addition, sufficient training to ensure the capacity of those who are expected to complete assigned tasks and standards are all-necessary for success. The relevant use of technology resources in the process of communication is also a critical component to ensure that school leaders maximize their communication efforts with all stakeholder groups. 


\section{METHODOLOGY}

This action research endeavor is a snapshot of what has become a series of focus groups made up of educational stakeholder groups designed to combine experimental approaches with the work of educators for the purpose of advancing theory and practice (Putman \& Rock, 2018). The researchers used a focus group of educators who were selected on a voluntary basis to share their perspectives on the topic of equity in education and technology during COVID-19 (Krueger, 1994). An interview protocol was developed with eight to ten questions for each of the three segments of the forum. These questions were developed to generate relevant responses and gather the perspectives of experienced educators from across the United States. The six panelist that made up the focus group were educational practitioners from a variety of states including New York, Virginia, Illinois, Alabama, and Louisiana. Follow-up questions could be asked by the other 40 plus educators who participated in the virtual forum during the five minute audience participation portion of each segment using the backchannel provided by the Zoom platform. The entire Zoom meeting was electronically recorded by the researchers and transcribed into a Word document. The transcripts were stored on electronic devices accessed by the researchers via secure passwords. The transcripts were analyzed as themes emerged and the researchers reviewed the recorded perspectives of the participants. A synthesized discussion of the themes that emerged follows in the next section.

\section{DISCUSSION}

What does equity in education and technology look like in schools during COVID-19? The COVID-19 pandemic illuminated inequities in education in regards to the accessibility and use of technology for marginalized students from across the United States. It was in the context of a forum that researchers and panelists explored equity in education related to accessibility of technology, accountability of stakeholder groups, and school leadership.

The forum panelists acknowledged some teachers struggled with converting from the physical face-to-face learning environment to the virtual learning environment, yet were able to be flexible and creative to provide a level of instructional rigor that enabled students to meet the established standards beyond standardized tests. The panelists emphasized that in light of the pandemic that traditional educational practices were changed by the instructional delivery methods, such as, remote, hybrid, and face-to-face. Equity in education as it relates to the accessibility of technology was found to be a major issue in some rural areas of the country such as in a variety of parishes in the state of Louisiana where broadband infrastructure was unavailable. In order to meet the demands of remote learning, the panelist agreed that school leaders needed to exhaust available resources, grants, and established partnerships to ensure that students receive high-speed internet services and technological devices including developmentally appropriate software. The expansion of the technological infrastructure across the United States would provide more equitable access to broadband services, thereby enhancing the potential for student success.

Equitable accountability for student progress during COVID-19 was the next area of focus for the virtual forum in regards to the responsibilities of principals, teachers, students, and parents. The panelists communicated that accountability needs to be the responsibility of school principals, teachers, parents, students, and community partners. While school principals were accountable for monitoring and evaluating teachers, they were equally responsible for ensuring resources were adequately distributed and utilized to support the delivery of rigorous instruction, and engaging community partners. Teachers were responsible for not only meeting students' instructional needs but their social emotional growth and parental engagement. Parental engagement was crucial to students meeting learning targets when clear expectations were communicated with parents and parents were fully trained on navigating devices, technological software, and platforms needed to support students' learning at home. Furthermore, student accountability was viewed from a task oriented lens that required students to not only attend class but be actively engaged in the learning environment in support of their learning. Students were required to have their cameras on, join breakout rooms, participate in small groups, engage in study lounges, while also completing tasks that provided teachers with the necessary assessment data. Community partners would provide available resources in support of the school's mission. The emerging theme for accountability aspect of the forum was an understanding that stakeholder groups are all in the learning process together and continuous communication is the foundation necessary to support academic achievement, as well as, meeting social and emotional needs. 
The forum panelists emphasized the critical importance of effective and efficient communication by school leaders, which will support the improvement of equity in school communities. Many school leaders struggled with leading and managing their schools because of the uncertainties surrounding COVID-19; however, greater equity in education could be realized by broadening the information sharing processes utilized within school communities. The ability of school leaders to articulate a clear direction for their school improvement plans with detail, while actively listening to and considering the needs of their students, teachers, and other stakeholders will go a long way in increasing the perceptions of equity. It would be advantageous for school leaders to create, develop, and keep an updated effective and efficient communication plan that is well known throughout the school community by all stakeholder groups.

\section{CONCLUSION}

Educators across the United States of America will agree that equity in education is the order of the day for our current system of education. It is the responsibility of all stakeholders to ensure students are provided instruction that meets their needs and that parents, teachers, students, and school leaders are actively engaged partners in the education process. The forum highlighted that a shift in education to ensure equity begins with communication, resources, authentic teaching, and moving beyond standardized testing. Equity in education during COVID-19, requires that all students, teachers, parents, and school leaders have access to relevant technology and are held accountable for the academic progress of all students. School leaders must become master communicators as they lead schools, teachers, and academic achievement efforts. Through established communicative relationships between and among principals, teachers, parents, students, and other stakeholder groups, equity in education will be at the forefront of increased academic achievement for all students. The COVID-19 pandemic highlighted inequities in education that has prompted educational stakeholders to begin to reimagine an improved educational system in the United States.

\section{ACKNOWLEDGEMENT}

We would like to acknowledge the Southeastern Louisiana University EDL 702 graduate students, Dr. Helen Stiff-Williams professor at Regent University, Virginia Beach, Virginia, Dr. Mary Fasbender retired superintendent of Cedar Rapids , Iowa, Dr. Nan Adams professor at Southeastern Louisiana University, Hammond, Louisiana, Dr. Takashi Crum teacher at New York City Department of Education, New York, New York, Dr. Toussaint Williams educator in Huntsville, Alabama, and Dr. Travis Ford principal Amite High School in Amite, Louisiana. You all's time and commitment to promoting equity in education across our great country is both admirable and greatly appreciated. Thank you!

\section{REFERENCES}

Brown v. Board of Education, 347 U.S. 483 (1954). https://www.loc.gov/item/usrep347483/

Domaleski, C. (2020). "The Impact of COVID-19 on ESSA." Centerline (49), April 7, 2020, https://www.nciea.org/blog/essa/outlook-essa-school-accountability-after-covid-19

Krueger, R.A. (1994). Focus Groups: A practical guide for applied research. Thousand Oaks, CA: Sage Publications.

Pew Research Center (2021). As schools close due to the coronavirus, some U.S. students face a digital homework gap'. https://www.pewresearch.org/fact-tank/2020/03/16/

Plessy v. Ferguson, 163 U.S. 537 (1896). https://www.loc.gov/item/usrep163537/

Puckett, C. \& Rafalow, M. (2020). COVID-19, Technology, and Implications of Educational Equity. American Sociological Association, 48(3). www.asanet.org

Putman, S.M. \& Rock, T. (2018). Action Research: Using strategic inquiry to improve teaching and learning. Thousands Oaks, CA: Sage Publications.

Schermerhorn, J. R. (1997). Situational Leadership: Conversations with Paul Hersey. Mid-American Journal of Business, Vol. 12, No. 2

U.S. Department of Education, Every Student Succeeds Act (2015), (https://www.ed.gov/essa?src=policy) 